\title{
Studies on Electrical Properties and Memory Retention Enhancement of Metal-Ferroelectric-Insulator-Semiconductor with Radical Irradiation Treatments
}

\author{
Le Van Hai ${ }^{1,2}$, Takeshi Kanashima ${ }^{1}$ and Masanori Okuyama ${ }^{1}$ \\ 1 Osaka University, \\ ${ }^{2}$ Hanoi University of Science and Technology, Viet Nam, \\ elpan
}

\section{Introduction}

Ferroelectric materials and their applications have been known and developed sine 1920s and nowadays they are one of the most important materials used in the memory, optical device and sensor device production. Although they are possible to utilize ferroelectric characteristics for a wide variety of applications, but a primary object of recent research activities is directed toward the development of nonvolatile memories. In this study we focused on enhancement of electrical and data retention characteristics of memory devices based on metal-ferroelectric-insulator-semiconductor (MFIS) structure by radical irradiation treatments.

Ferroelectric memories has gathered much attention since they show ultimate properties of nonvolatility, low-power consumption, and high-speed operation [Hai, L. V., etc. (2010), Hai, L. V., etc. (2006 a), Tarui Y, ect. (1997), Scott, J. F. (2000), Sakai, S. \& Ilangovan, R. (2004), Ishiwara, H. (2001)]. The well-known ferroelectric memory applications of ferroelectric capacitor-type random access memories (FeRAM) have been successfully developed and commercially available at present [Sakai, S. etc. (2010)]. Another type of ferroelectric memory is a ferroelectric field effect transistor (FeFET), in which a ferroelectric layer was inserted between top gate and oxide layer of an FET, as shown in. In recent years, memory cells of the FeFETs were selected as the most suitable candidate to alternate for floating-gate (FG) memory cells in the NAND flash memory, due to the fact that FeFET cells exhibited superior characteristics from viewpoints of downscale ability, long endurance characteristics, and low-voltage operation, in comparison with the FG-cells [Hai, L. V., etc. (2010)]. The new Fe-NAND flash memory based on the FeFETs can open a new generation of the NAND flash memory which meets fully requirements of high speed USB flash drives, MP3 players, flash memory in portable devices and solid-state drive (SSD) applications [Hai, L. V., etc. (2010)]. Although many efforts have been made by many research groups to improve but the FeFET-type memories still need more investigations to satisfy for commercial application as some problems were pointed out. It is extremely difficult to fabrication FeFETs with high-quality ferroelectric and insulator films therefore they always do not show acceptable retention and electrical properties. We attribute the relatively low- 
quality films to diffusion of constituent elements. The diffusion between the ferroelectric film and insulator layer has given damages to interface layers, such as the formation of highdensity electron or hole surface traps and charge injection into the ferroelectric layer, which seriously degrade device performance because of increases in leakage current and depolarization field [Takahashi, M. (2001)]. In addition, the element diffusions between layers in MFIS stack during fabrication process cause mainly stoichiometric composition change, and lead to quality degradation of insulator and ferroelectric films.

Among potential candidates of gate structure for MFIS-type FET, Pt/SBT/SiO$/ \mathrm{Si}_{2} / \mathrm{Stack}$ is the simplest structure, good matching with complementary metal-oxide-semiconductor (CMOS) process [Paz de Araujo, C.A., etc., (1995), Hai, L. V., etc. (2006 b)] and low-cost production. $\mathrm{SiO}_{2}$ buffer layer was grown simply by thermal oxidation method directly on $\mathrm{Si}$ substrate, and did not need a special buffer layer of high-k material which requires a complicate process and unfamiliar with the convenience silicon manufacturing process. It made $\mathrm{Pt} / \mathrm{SBT} / \mathrm{SiO}_{2} / \mathrm{Si}$ stack give advantage in comparison with the other MFIS structures. But the $\mathrm{SiO}_{2}$ buffer layer has a small dielectric constant and is not good as diffusion barrier layer in comparison with high-k material $\left(\mathrm{Si}_{3} \mathrm{~N}_{4}, \mathrm{Al}_{2} \mathrm{O}_{3}, \mathrm{HfO}_{2}, \mathrm{HfAlO}\right.$, etc.) [Aizawa, K., etc. (2004), Sakai, S. etc. (2004), Youa, I.-K., etc., (2001)]. To overcome these challenges, We have suggested a novel method of using nitrogen radical irradiation to treat the $\mathrm{SiO}_{2}$ buffer layer in MFIS structure [Hai, L. V., etc. (2008)]. The $\mathrm{SiO}_{2}$ layer shows enhancements of dielectric constant and thermal stability, and becomes a good buffer layer for suppressing the constituent element diffusion problem. These achievements were demonstrated through our experiment results.

Furthermore, nitrogen and oxygen radical irradiation treatments were employed to modify surfaces of ferroelectric layer for the first time [Hai, L. V., etc. (2006 a)]. We found that ferroelectric interface layers have been formed and demonstrated promising properties of barrier layers. Furthermore, dielectric constant of buffer layer increases, and so depolarization field will be suppressed. It is reported that it could significantly suppress the diffusion of ferroelectric components or chemical reactions with nitrogen treatment [Hai, L. V., etc. (2006 a)]. As a result, the nitrogen radical irradiation treatment is a significant candidate for improving memory retention characteristic of the Pt/SBT/ $\mathrm{SiO}_{2} / \mathrm{Si}$ MFIS.

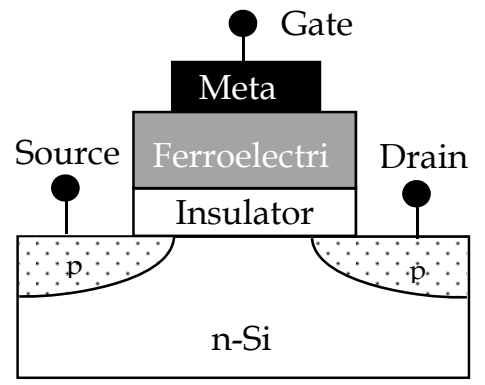

Fig. 1. Schematic of ferroelectric gate FET on n-Si substrate

The goal of this work is to solve the main problems of MFIS structure, namely large leakage current and short retention time, to realize ferroelectric memory applications with the feature of non-destructive readout [Hai, L. V., etc. (2010), Hai, L. V., etc.(2006 a), Tarui Y, ect. (1997), Scott, J. F. (2000), Sakai, S. \& Ilangovan, R. (2004), Ishiwara, H. (2001)]. The study results include: demonstrations of the simplest MFIS structure with good characteristics for ferroelectric memory application; using a novel method of radical irradiation to enhance 
electrical characteristics of MFIS structures such as, decrease of leakage current and improvement of retention property from 3 hours to 23 days.

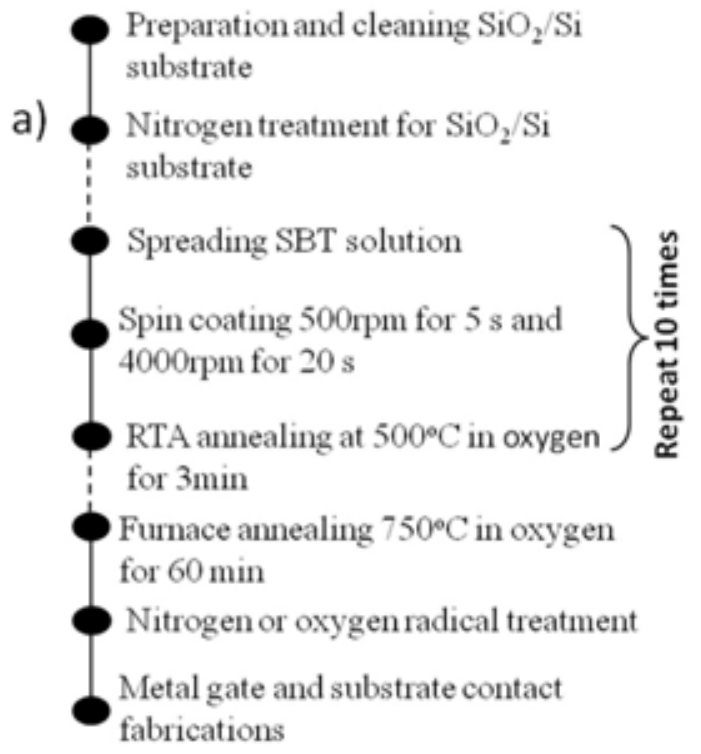

b)

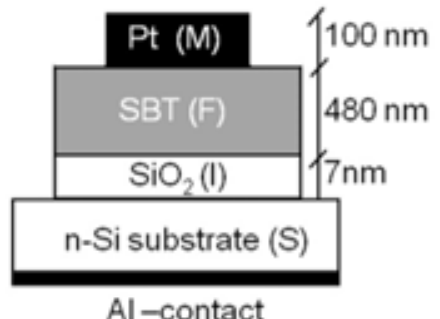

Al-contact

Fig. 2. a) Schematic of fabrication steps for MFIS structure and b) cross-section of and parameters of MFIS stack.

\section{Structure and Fabrication processes of Metal-ferroelectric-insulator- semiconductor}

\subsection{Structure of MFIS devices}

The present FeFET structures like the metal-oxide-semiconductor field effect transistor (MOSFET), in which a ferroelectric layer was inserted between top metal gate and an insulator layer, as shown in Fig. 1. The principal structure of the FeFETs are composed from a MFIS stack of metal, ferroelectric, insulator, semiconductor layer, as in Fig. 2b . In a FeFET, polarization direction of the ferroelectric layer depends on application voltages of the gate and drives the drain current between the source and drain regions.

The $\mathrm{SiO}_{2}$ insulator of thickness $7.5 \mathrm{~nm}$ was prepared directly from the $\mathrm{n}-\mathrm{Si}$ semiconductor substrate by thermal oxidization method beforehand. Substrate with $\mathrm{SiO}_{2}$ layer on surface was cleaned by high purity acetone, propanol and deionized-water in ultra-sonic cleaner before treating by radical irradiation, which will be described in more detail in next section.

\subsection{Fabrication of the MFIS stack}

First, SBT ferroelectric thin film was prepared on the substrate by metal-organic decomposition method (MOD). The SBT solution used for the MOD was Y-1 type0 (Sr:Bi:Ta $=$ 0.9:2.2:2.0) manufactured by Kojundo Chemical Lab. Co. Ltd. Si substrate with $\mathrm{SiO}_{2}$ buffer 
layer was coated with SBT solution by spin-coating method, at $500 \mathrm{rpm}$ for $5 \mathrm{~s}$ and subsequently rotated at $4000 \mathrm{rpm}$ for $30 \mathrm{~s}$. Then, the films were dried at $160^{\circ} \mathrm{C}$ for $3 \mathrm{~min}$ by hot plate in atmosphere and subsequently annealed in $\mathrm{O}_{2}$ by rapid thermal annealing (RTA) for $3 \mathrm{~min}$ at $700^{\circ} \mathrm{C}$ for. This step was repeated 10 times to achieve $480-\mathrm{nm}$ thickness of SBT thin film. Finally, the SBT thin film was atreated at $750^{\circ} \mathrm{C}$ by furnace annealing in $\mathrm{O}_{2}$ ambience for $60 \mathrm{~min}$ to crystallize SBTs. To enhance basic property of thin film, the SBT were treated in vacuum chamber by nitrogen or oxygen radical irradiation which will be described in more detail in the next section. The Pt circle electrodes were prepared by Ar plasma sputtering method on the SBT thin films with diameter of $150 \mu \mathrm{m}$. The Al substrate contact on the back-side of the n-Si substrate was prepared by thermal evaporation.

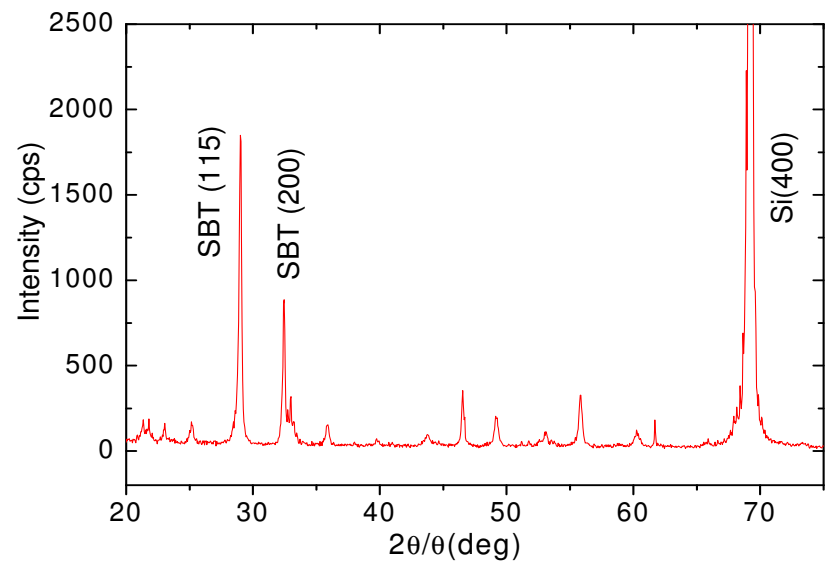

Fig. 3. X-ray diffraction pattern for SBT film grown on $\mathrm{SiO}_{2} / \mathrm{n}-\mathrm{Si}$ substrate by MOD method and treated by furnace annealing in oxygen ambience at ate $750^{\circ} \mathrm{C}$ for $60 \mathrm{~min}$.

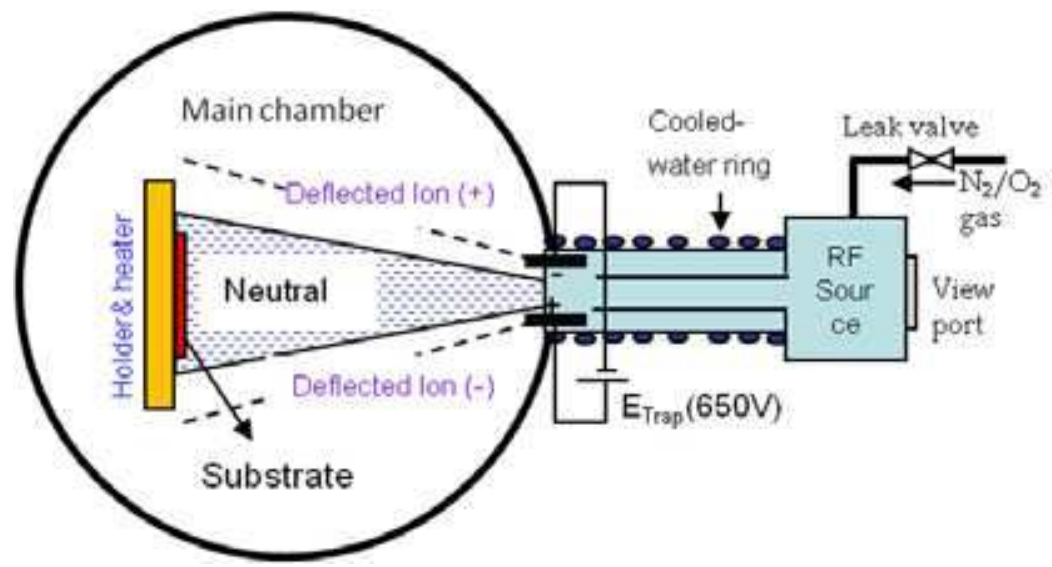

Fig. 4. Schematic diagram of radical irradiation system. 


\subsection{X-ray diffraction characterization of SBT thin films}

X-ray diffraction (XRD) pattern of SBT thin films deposited on $\mathrm{SiO}_{2} / \mathrm{n}-\mathrm{Si}$ substrates is shown in Fig. 3. The SBT thin film was treated at $750^{\circ} \mathrm{C}$ by furnace annealing in $\mathrm{O}_{2}$ ambience for 60 $\mathrm{min}$. The thickness of the SBT is about $480 \mathrm{~nm}$. It can be observed that SBT film deposited on $\mathrm{SiO}_{2} / \mathrm{n}$-Si shows a highly textured (115) orientation and a minor textured (200) orientation. Some reports of SBT thin films have revealed that typical peak of SBT(115) at $2 \theta=29.00$ is Bilayered peroskite structure and (222) peak of the pyrochlore SBT is at $2 \theta=29.45$ [J.C.Riviere (1983)]. The figure shows no diffraction peaks from pyrochlore phase.

\section{Treatments of nitrogen and oxygen radical irradiation}

The nitrogen and oxygen radical irradiation systems employed in this study is shown in Fig. 4. Nitrogen/oxygen radical was generated within a small tube of pyrolytic boron nitride (PBN) by an RF radical gun. When pure nitrogen/oxygen was introduced to the tube with a leak valve into the radical gun, Nitrogen/oxygen plasma was formed and the nitrogen/oxygen radicals were injected into treatment chamber due to the pressure difference between the treatment chamber and radical gun inside. The RF source operates at $13.56 \mathrm{kHz}$ with a typical maximum power of $600 \mathrm{~W}$.

The nitrogen or oxygen radical beam was injected the into the main chamber through an ion trap, which repels ions with a strong voltage of $-650 \mathrm{~V}$. Ions are almost bent in way to treatment chamber wall when travelling through the ion trap space and never approaching sample. As a result only neutral species of nitrogen or oxygen can go straight and approach at surface of substrate, because they are not Affect by electric field. The substrate was attached on a holder and its surface is perpendicular to the radical beam. Temperature of back-side of substrate was controlled and kept constant during treatment by a heater source.

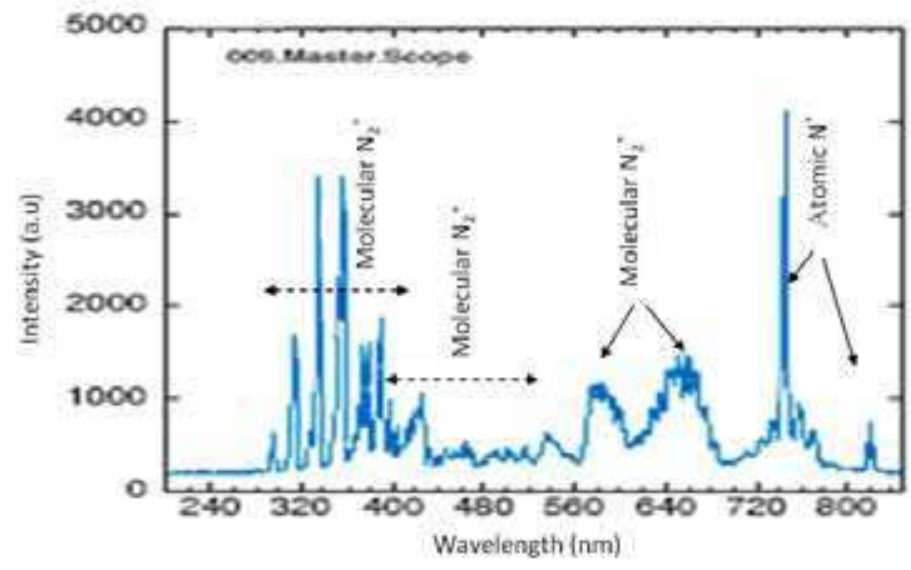

Fig. 5. Optical emission spectrum of RF plasma source operating with $400 \mathrm{~W}$, and using 0.56 Sccm nitrogen at chamber pressure of $7 \times 10^{-3} \mathrm{~Pa}$

Fig. 5 shows emission spectrum of the radical source monitored from a quartz window at the end of the radical source. The nitrogen radicals supplied by the radical source are mainly composed of excited molecular neutral $\left(\mathrm{N}_{2}{ }^{*}\right)$ and atomic neutral $\left(\mathrm{N}^{*}\right)$ nitrogen with a small 
amount of molecular $\mathrm{N}_{2}$ and atomic $\mathrm{N}$ ions. The intensity of $\mathrm{N}^{*}$ and $\mathrm{N}_{2}{ }^{*}$ drastically depends on nitrogen flow rate, chamber pressure and the power applied to the radical gun. In this study, we optimized optical emission spectra of nitrogen radical as show in Fig.5. Neutral elements were dominated by optimized parameters in Table 1. Better nitrogen treatment performance can be obtained with high intensity ratios of $\mathrm{N}^{*}$ and $\mathrm{N}_{2}{ }^{*}$.

\begin{tabular}{|c|c|c|}
\hline Parameters & $\begin{array}{c}\text { Nitrogen radical } \\
\text { irradiation }\end{array}$ & $\begin{array}{c}\text { Oxygen radical } \\
\text { irradiation }\end{array}$ \\
\hline RF power & $400 \mathrm{~W}$ & $300 \mathrm{~W}$ \\
\hline Reflected power & $1 \mathrm{~W}$ & $3 \mathrm{~W}$ \\
\hline Chamber pressure & $7 \times 10^{-3} \mathrm{~Pa}$ & $8 \times 10^{-3} \mathrm{~Pa}$ \\
\hline Substrate temperature & $400{ }^{\circ} \mathrm{C}$ & $400 \circ \mathrm{C}$ \\
\hline Gas flow & $0.56 \mathrm{Sccm}$ & $1 \mathrm{Sccm}$ \\
\hline
\end{tabular}

Table 1.Typical conditions of nitrogen and oxygen radical irradiation treatments

\section{Nitrogen radical irradiation treatments for enhancement of property of $\mathrm{SiO}_{2}$ thin film}

\subsection{Chemical composition of $\mathrm{SiO}_{2}$ with nitrogen radical irradiation treatments}

After nitrogen treatment, the $\mathrm{SiO}_{2} / \mathrm{n}$-Si substrates were annealed for $30 \mathrm{~min}$ at $950{ }^{\circ} \mathrm{C}$ in nitrogen ambience in furnace to remove fixed charges which were generated during irradiation of $\mathrm{SiO}_{2}$ surface. Nitrogen incorporated on surface of $\mathrm{SiO}_{2}$ film were confirmed by surface chemical analysis from x-ray photoelectron spectroscopy (XPS) spectrum.

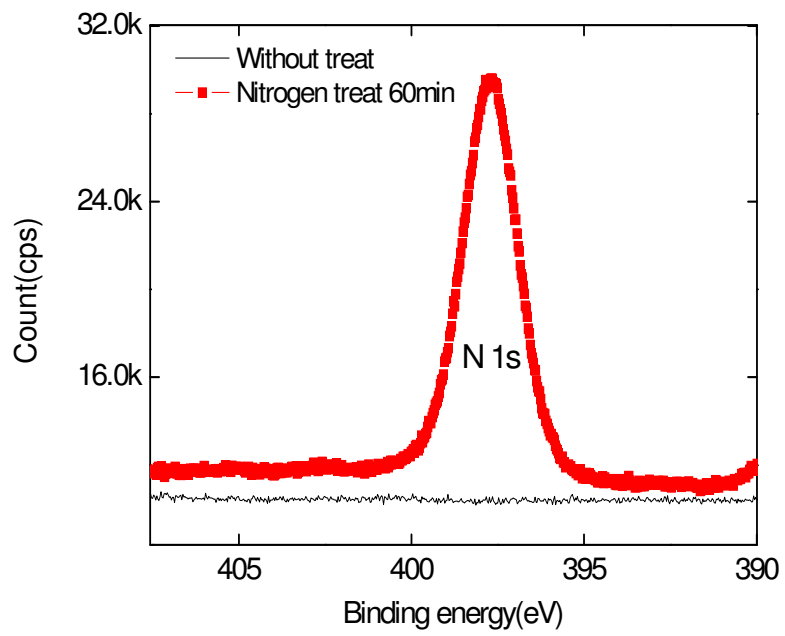

Fig. 6. XPS spectra of $\mathrm{N} 1 \mathrm{~s}$ state of $\mathrm{SiO}_{2}$ surface with and without radical treatment for $60 \mathrm{~min}$. 
Figure 6 shows XPS spectra near N1s state of $\mathrm{SiO}_{2}$ surface with and without radical treatment. The distribution of the nitrogen concentration near surface of nitrided $\mathrm{SiO}_{2}$ layer was obviously observed by comparing the intensity of N1s peaks near $398 \mathrm{eV}$. It was one of evidence to prove incorporation of nitrogen in $\mathrm{SiO}_{2}$. Nitrogen radicals make bonding with $\mathrm{SiO}_{2}$ surface and form $\mathrm{SiON}_{x}$ [Hai, L. V. etc., (2006)].
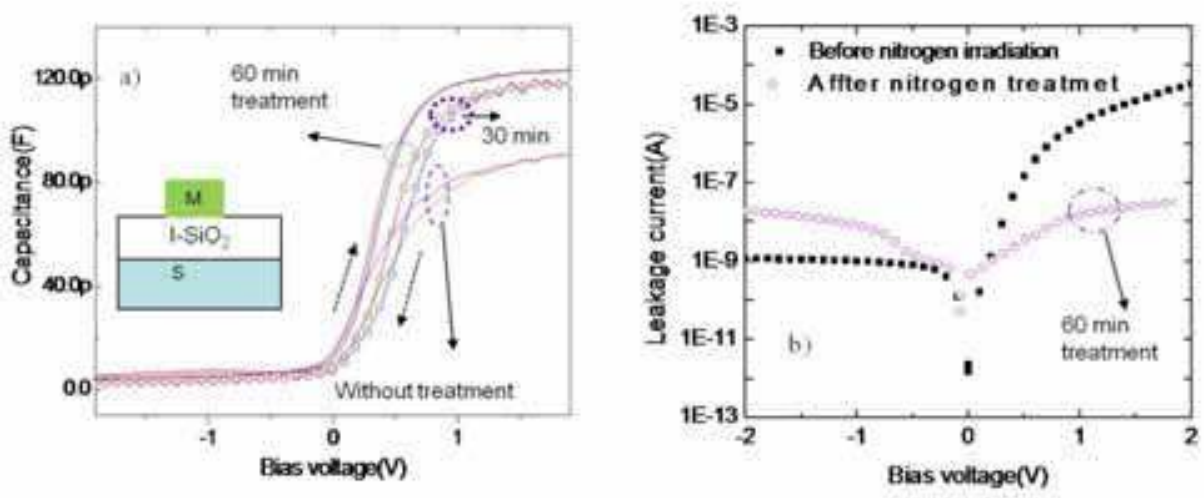

Fig. 7. Electronic properties of $\mathrm{Pt} / \mathrm{SiO}_{2} / \mathrm{Si}$ MIS diodes with top electrode size of $7 \times 10^{4} \mu \mathrm{m}^{2}$, a) C-V curves of MIS withwith nitrogen treatment $60 \mathrm{~min}, 30 \mathrm{~min}$ and without the treatment, and b) I-V curves of MIS with 60 min and without nitrogen treatment.

\subsection{Electrical characteristics of MIS diodes with nitrogen radical treatment}

Figure 7 shows $\mathrm{C}-\mathrm{V}$ and I-V characteristics of MIS diodes which have 7.5-nm $\mathrm{SiO}_{2}$ insulator layer with and without nitrogen radical. Fig. 7 a) shows capacitance of the MIS structure with different nitrogen treatment period of $\mathrm{SiO}_{2}$ film. It is confirmed that dielectric constant of insulator layer increases also due to treatment process.

Besides C-V curve improvements, Fig. 7 b) shows the I-V characteristic of sample improved by $60 \mathrm{~min}$ nitrogen treatment in comparison with sample without treatment. It is believed that neutral nitrogen is incorporated with $\mathrm{SiO}_{2}$ forming $\mathrm{SiON}$ and improves the electrical properties of the insulator layer. All C-V curves of samples with nitrogen treatment show steep transition region and a small hysteresis, while sample without nitrogen treatment has gently sloping and hysteresis in $\mathrm{C}-\mathrm{V}$ curve which is induced by carrier injection. Furthermore, it was also confirmed that $\mathrm{SiO}_{2}$ without treatment generates promotion of positive-shift in $\mathrm{C}-\mathrm{V}$ curve, compared with MIS structures using $\mathrm{SiO}_{2}$ with nitrogen treatment for $30 \mathrm{~min}$ or $60 \mathrm{~min}$. It is well known that the positive-shift of the flat-band voltage in $\mathrm{SiO}_{2}-\mathrm{MOS}$ systems can result from the negative charge trapping in the oxide layer. We believed nitrogen radical treatment is helpful to reduce negative charge trapping in $\mathrm{SiO}_{2}$ layer. That means the improvements of the $\mathrm{Si} / \mathrm{SiO}_{2}$ interface properties and decrease of negative charge density in the $\mathrm{Si} / \mathrm{SiO}_{2}$ were a primary cause of C-V curve improvements. 


\section{Nitrogen and oxygen radical irradiation treatment for SBT ferroelectric layer}

5.1 Surface morphologies of SBT thin films with nitrogen irradiation treatments

During treatment decrease of oxygen vacancies density in the surface of $\mathrm{Si} / \mathrm{SiO}_{2}$ were primary causes of $\mathrm{C}-\mathrm{V}$ curve improvements. The decrease of oxygen vacancies density could help to suppress the $\mathrm{Bi}$ and other elements from $\mathrm{SBT}$ layer in to $\mathrm{SiO}_{2}$ insulator layer in MFIS structure. Because they react with vacancies in the $\mathrm{SiO}_{2}$, forming fast-moving complexes [Klee, M. and Macken, U. ( 1996) ; Tanaka, M. ect. 1998].

Fig. 8 shows SEM micrographs of $\mathrm{SrBi}_{2} \mathrm{Ta}_{2} \mathrm{O}_{9}$ thin films with and without nitrogen treatment. Voids are observed all over the surfaces of the films as there appear different density and size. Surface morphology of as-deposited SBT was not satisfied with many deep voids. However surface morphologies of treated SBT have been remarkably improved by the radical irradiation and the deep voids disappear from the film surfaces, resulting in smooth surfaces. In particular, the film surface morphologies which were investigated by AFM images have confirmed the roughness improvement (Fig. 9). This figure shows the roughness rapidly reduces with the nitrogen radical for $10 \mathrm{~min}$ and slowly reduces with increasing irradiation time.

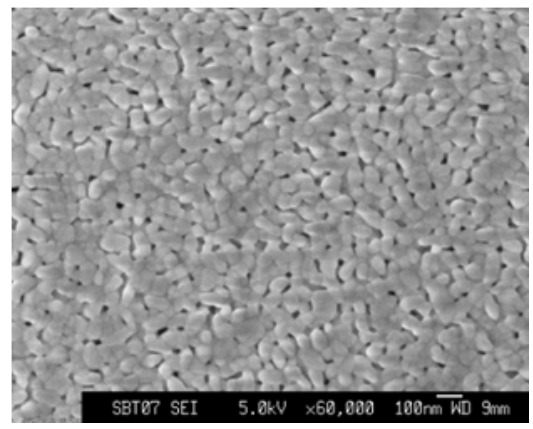

a) SBT without treatment

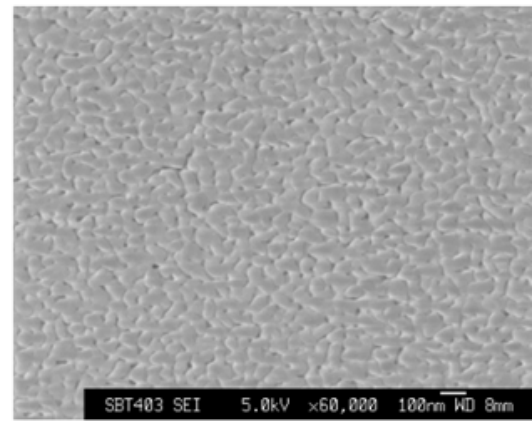

c) SBT with $40 \mathrm{~min}$ treatment

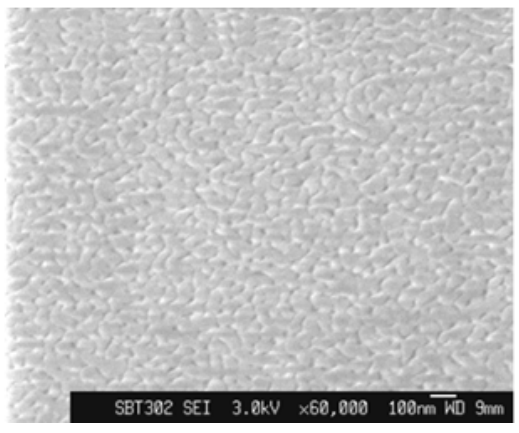

b) SBT with 20min treatment

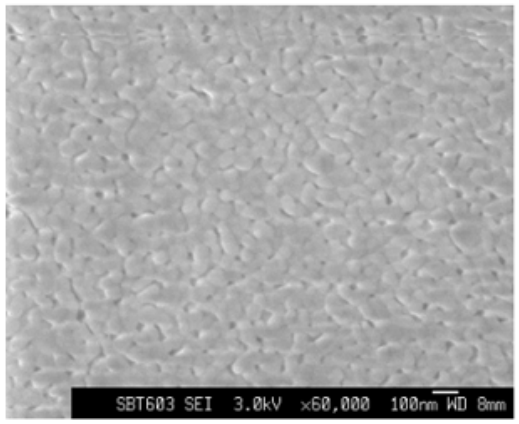

d) SBT with $60 \mathrm{~min}$ treatment

Fig. 8. SEM micrographs of surface SBT thin films a) as-deposited, after nitrogen treatment b) for $20 \mathrm{~min}, \mathrm{c}$ ) for $40 \mathrm{~min}$, and d) for $60 \mathrm{~min}$. 


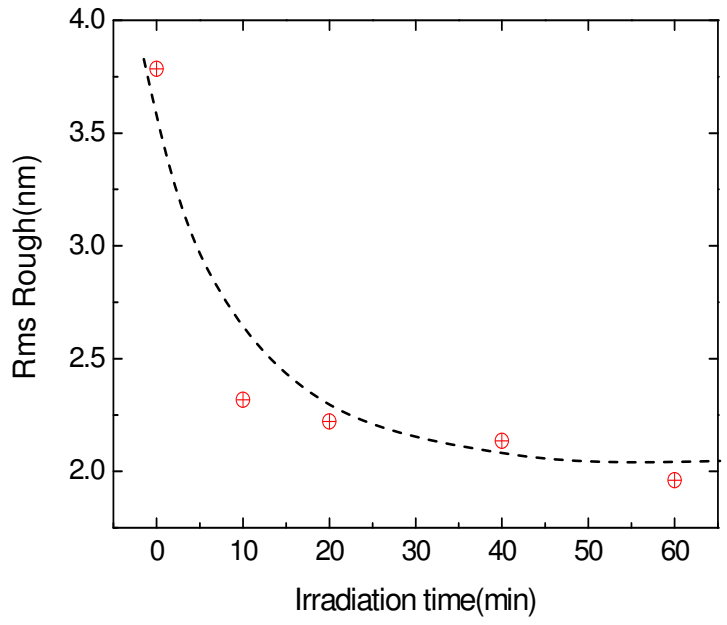

Fig. 9. Surface morphology roughness of SBT thin films and versus treatment time of nitrogen radical irradiation

\subsection{Chemical modification of surface SBT thin films induced by nitrogen irradiation}

Fig. 10 shows XPS spectra of N1s state of the SBT surfaces with and without radical treatments. As N1s peak intensity which corresponds to nitrogen density of in SBT surface, reaches the maximum value and then reduces with treatment time. The highest nitrogen density can be obtained when irradiation time is around $20 \mathrm{~min}$.

It is suggested that nitrogen is initially incorporated with $\left(\mathrm{Bi}_{2} \mathrm{O}_{2}\right)^{2+}$ oxide layer, and replaced oxygen vacancy in defect $\left(\mathrm{Bi}_{2} \mathrm{O}_{2}\right)^{2+}$ layer, and even oxygen in $\mathrm{Bi}-\mathrm{O}$ bonding. If SBT surface was irradiated for long time, it will be damaged by irradiation beam. Appearance of nitrogen on SBT films perhaps modifies energies of Bi-O bonds and N1s state in comparison with general states of them. Binding energy of $\mathrm{O}$ and Bi slightly shifts toward lower energy, as XPS spectra of O1s and Bi4f states of the SBT surface shown in Fig. 11. Authors suggested that is due to electro negativity of N-bond (3.04) is smaller than that of O-bond (3.44) and in surface of the SBT layer a small amount of nitrogen atom replace for oxygen atom in $\mathrm{Bi}-\mathrm{O}$ bond. We found production of oxygen vacancies or free $\mathrm{Bi}$ in $\left(\mathrm{Bi}_{2} \mathrm{O}_{2}\right)^{+2}$ layer induces a problem in SBT films after thermal crystallization and some interested effects in SBT layer treated by nitrogen radical [Hai, L. V., Kanashima, T., Okuyama, M. (2006 b)]. Work-function and band gap of the SBT surface layer were modified. Barrier energy heights for hole in M-F junction increased, and so the electronic properties of the SBT layer were improved. Composition of SBT surface was changed with decrease of free $\mathrm{Bi}^{0}$ density. It is considered that oxygen vacancies can be suppressed by nitrogen treatment, because neutral nitrogen radical forms stronger bonding than oxygen and easily reacts with free Bi that remains after crystallization in oxygen. In this study, we found maximum work-function energy of $6.6 \mathrm{eV}$ belongs to SBT film after 20 min nitrogen treatment. 


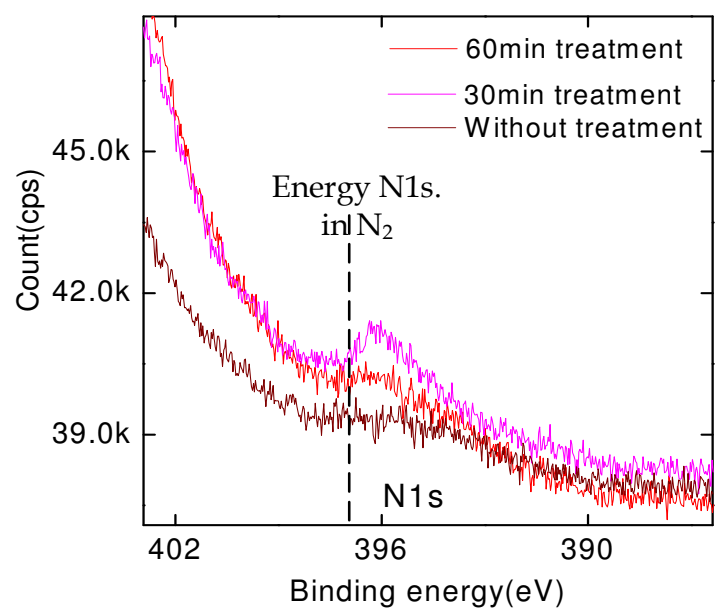

Fig. 10. XPS spectra of N1s state of the SBT surface without and with radical treatment in 30 and $60 \mathrm{~min}$.
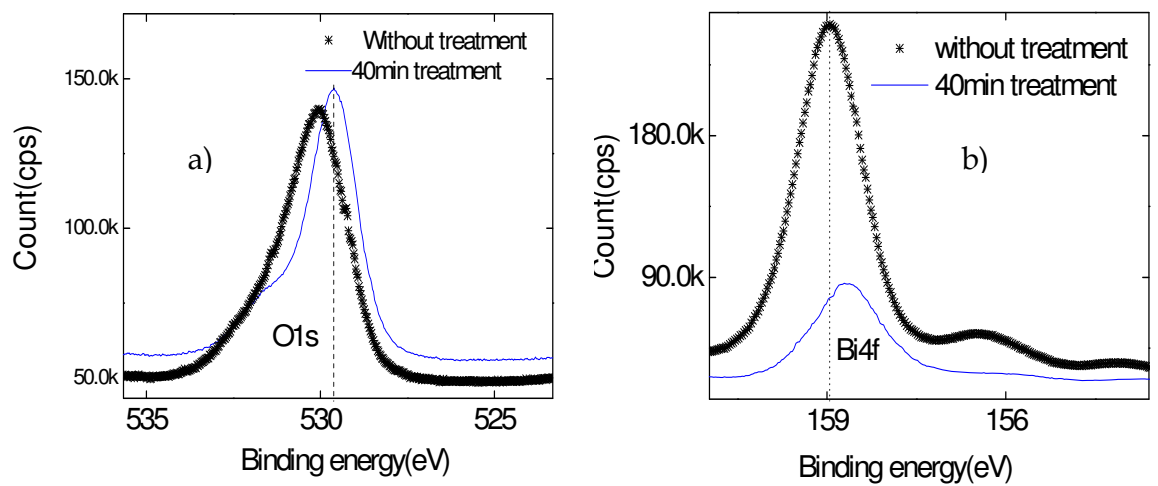

Fig. 11. XPS spectra of SBT before and after irradiation treatment. a) O1s spectra peaks and b) Bi 4 f spectra peaks.

\subsection{Effect of radical treatments on SBT band gap}

X-ray photoelectron spectroscopy (XPS) was used to investigate the binding and composition states of SBT before and after radical treatment. Figure 13 a) shows electron energy levels explaining a typical photo-emission. The binding energies are decided by comparison with carbon peak. The range is concerned with Bi binding, particularly the peaks near $160 \mathrm{eV}$ and $165 \mathrm{eV}$ are attributed to the oxidized $\mathrm{Bi}^{3+}$ of $-\mathrm{Bi}-\mathrm{O}$ binding, 157 and $163 \mathrm{eV}$ are attributed to the metallic $\mathrm{Bi}^{0}$ of Bi-metal binding. From the $\mathrm{Bi} 4 f$ XPS spectra of Fig. 12, it is clear that the Bi metallic peaks are affected by nitrogen and oxygen irradiation 
time, and disappear after $10 \mathrm{~min}$ or 20 min treatment, respectively. This behavior indicates that the metallic ion can be reduced by nitrogen or oxygen irradiation. Owning to decrease of metallic Bi atom and Bi defect ion on the surface of thin film, the Bi diffusion - the main reasons of poor metal-ferroelectric interface, should be suppressed. During treatment, a series of chemical reactions took place on the surface of SBT and modified chemical bonding of surface layer.

Fig. 13 b), c) and d) show the O1s XPS peak of both SBT thin films with radical treatment. The O1s XPS signal includes two peaks of oxygen in perovskite structure on the right side with a smaller energy binding and oxygen in the bismuth-deficient $\left(\mathrm{Bi}_{\mathrm{x}} \mathrm{O}_{\mathrm{y}}\right)$ layers on the left side with a larger binding energy. In this figure, the O1s spectra of perovskite structure shifts toward smaller binding energy and $\mathrm{O} 1 \mathrm{~s}$ spectra of oxygen in bismuth-deficient $\left(\mathrm{Bi}_{\mathrm{x}} \mathrm{O}_{\mathrm{y}}\right)$ become smaller with the treatment. That means the oxygen vacancy in the defected $\left(\mathrm{Bi}_{\mathrm{x}} \mathrm{O}_{\mathrm{y}}\right)$ layers is reduced by nitrogen or oxygen irradiation.

The energy loss spectra of O1s peaks for SBT films have been analyzed to estimate their band gaps between the valence bands and conduction bands. H. Itokawa, et al, discussed on determinations of band gap by analyzing XPS spectral of $\mathrm{O}$ 1s core levels for several insulators. The band gap of $4.20 \mathrm{eV}$ is assumed for as-deposited SBT film [Takahashi, M. etc., (2001)]. Fig.s 13 show XPS spectra to estimate band gap of the surface layer of the SBT treated by nitrogen, oxygen irradiation and as-deposited. In results, band gap of $4.20 \mathrm{eV}$ of as-deposited SBT film was confirmed, Fig. $13 \mathrm{~b}$ ). After 20 min oxygen irradiation band gap energies of SBT of was increased from $4.20 \mathrm{eV}$ to of $4.52 \mathrm{eV}$, Fig. $13 \mathrm{c}$ ).. After $10 \mathrm{~min}$ nitrogen irradiation band gap energies of SBT of was increased from $4.20 \mathrm{eV}$ to of $4.72 \mathrm{eV}$, Fig. 13 d).

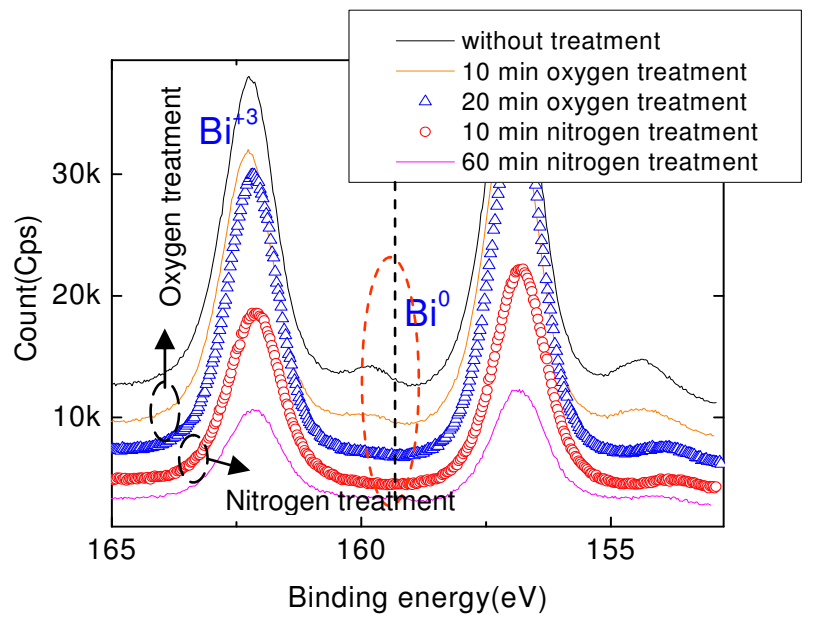

Fig. 12. XPS spectrum near the Bi 4 f peaks of SBT film surface with and without radical treatments. 

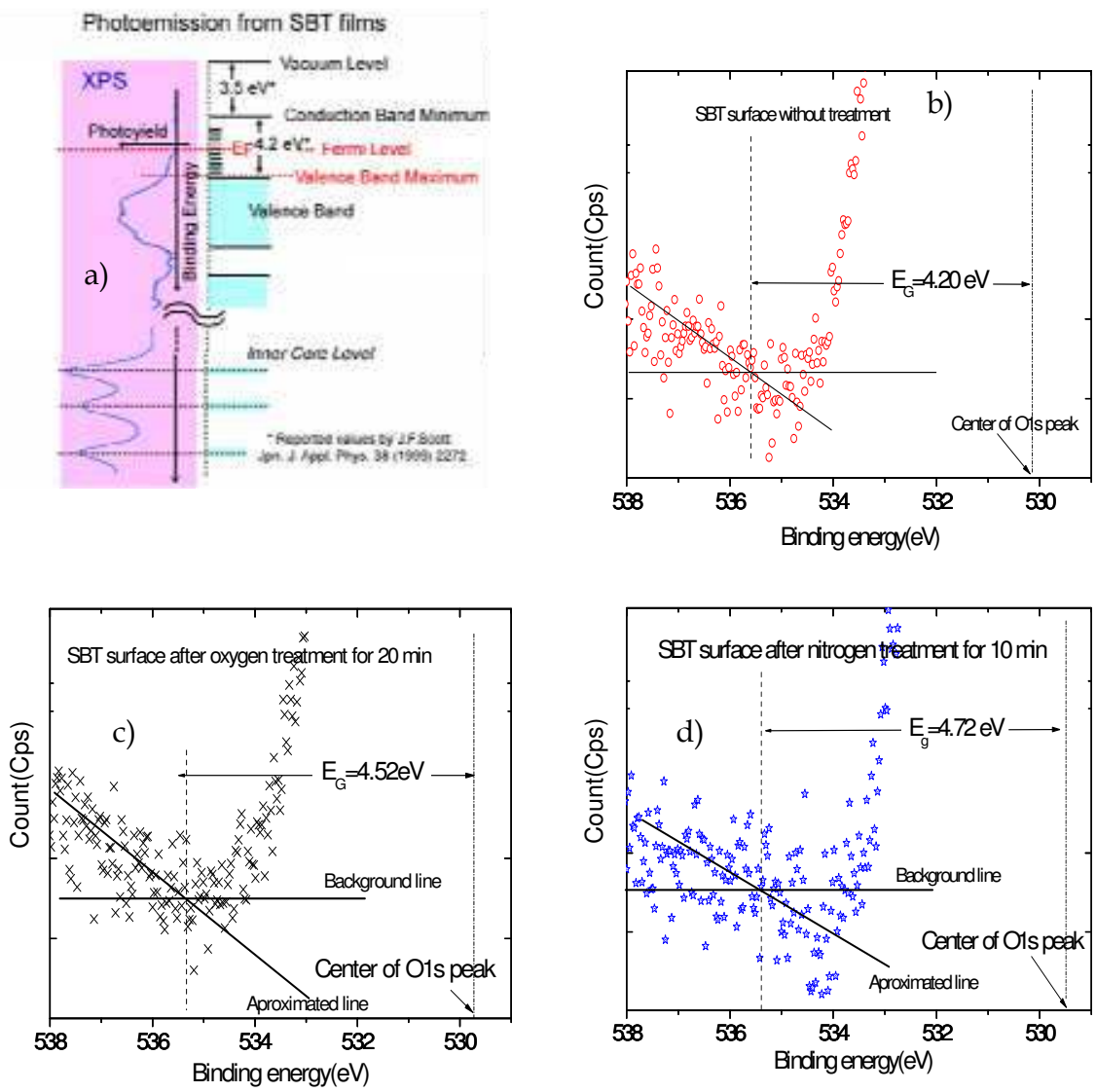

Fig. 13. a) Electron energy levels explaining a typical photo-emission, and XPS spectra of SBT before and after irradiation treatment near O1s spectra peak for b) as-deposited film, c) 20-min oxygen treated and d) 10-min nitrogen radical treated films. Band gap width of SBT were calculated from $\mathrm{O}$ 1s core levels

\subsection{Effect of radical treatments on Fermi level of SBT thin films}

Fermi level energies could be estimated for all nitrogen-treated, oxygen-treated and asdeposited SBT thin films by analyzing their ultraviolet-ray photoyield spectroscopy (UVPYS) spectra [Takahashi, M., (2003)]. From Fig. 14, Fermi level energy of $5.24 \mathrm{eV}$ was obtained for the as-deposited SBT thin film and it increases due to nitrogen and oxygen irradiation treatments. In estimation, the Fermi level energy of the SBT thin films treated by oxygen and nitrogen radicals are about $5.50 \mathrm{eV}$ and $5.60 \mathrm{eV}$, respectively. The barrier height of the SBT surface with other layers depends on Fermi level energy of the SBT so absolutely the leakage current through $\mathrm{Pt} / \mathrm{SBT} / \mathrm{SiO}_{2}$ will be affected. A detail of this problem will be explained in the nextdiscussion. 


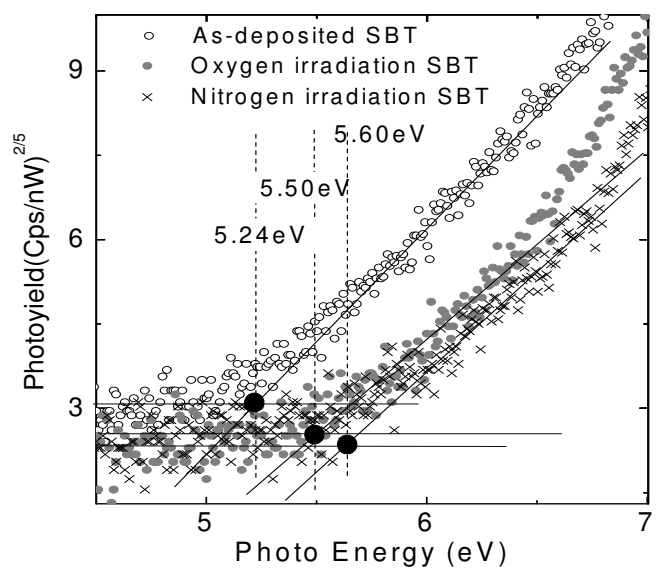

Fig. 14. UV-PYS spectra and estimation of Fermi level in as-deposited and irradiated SBT thin films irradiate by oxygen and nitrogen radicals.
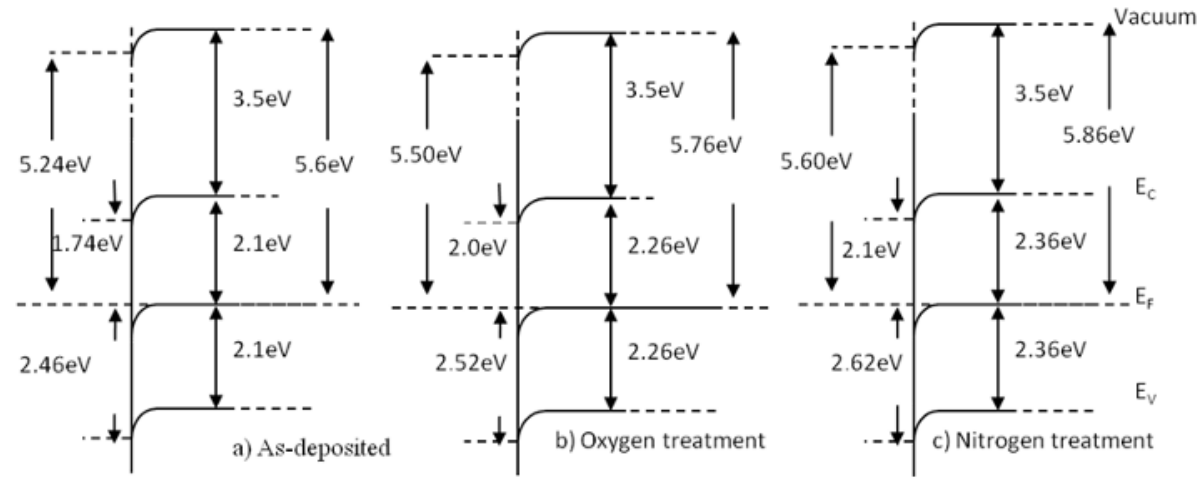

Fig. 15. Band diagrams considered formed-SBT surface before and after irradiation treatment, (a) As-deposited, (b) oxygen radical treatment, and (c) nitrogen radical treatment.

\subsection{Calculation of energy diagrams formed-SBT surface with irradiation treatment}

From the results of UV-PYS and XPS measurements, we can suggest that a new and very thin layer was formed on surface of the SBT thin film after nitrogen or oxygen irradiation treatment. The composition states of this layer were modified and different from that of the as-deposited SBT thin film. It is considered that both metallic Bi and oxygen vacancy in defected layer $\left(\mathrm{Bi}_{\mathrm{x}} \mathrm{O}_{\mathrm{y}}\right)$ were reduced, that are major causes for modifying the band gap and Fermi level. Band diagrams are considered for SBT surfaces before and after nitrogen irradiation, shown in Fig. 15. If electron affinity of $3.5 \mathrm{eV}$ is assumed for SBT [Klee, M. and Macken, U. (1996).], differences in energy between the Fermi-level and the conduction band 
minimum, which is considered to be the barrier height for electrons at the metalferroelectric interface, are estimated at $1.74 \mathrm{eV}$ for the as-deposited film, $2.00 \mathrm{eV}$ for the oxygen-treated film and $2.10 \mathrm{eV}$ for the nitrogen- treated film. On the other hand, the hole barrier heights are estimated at $2.46 \mathrm{eV}$ for the as-deposited film, 2.52 and $2.62 \mathrm{eV}$ for oxygen and nitrogen irradiation treatment films, respectively.

Fig. 15 suggested barrier versus both electrons and holes that describes the effect of the radical treatment on the SBT surface. Both band offsets for electrons and holes are increased slightly, that means the leakage current will be suppressed.

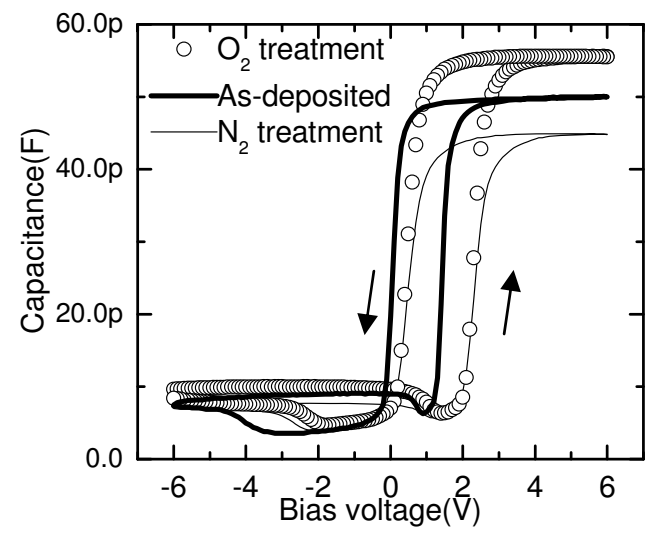

Fig. 16. C-V characteristics of MFIS structures using SBT films with and without irradiation treatments

\subsection{Improvements of electrical characteristics of $\mathrm{Pt} / \mathrm{SBT} / \mathrm{SiO}_{2} / \mathrm{n}-\mathrm{Si} \mathrm{MFIS}$ by application of nitrogen and oxygen radical treatment to SBT layer}

Fig. 16 shows the $\mathrm{C}-\mathrm{V}$ hysteresis characteristics of the $\mathrm{Pt} / \mathrm{SBT} / \mathrm{SiO}_{2} / \mathrm{n}-\mathrm{Si}$ structure with asdeposited SBT film, or SBT film after oxygen treatment for $20 \mathrm{~min}$ and nitrogen treatment 10 min, which were measured by sweeping the gate voltage from inversion to accumulation region and then sweeping back. The sweeping voltage changes between $\pm 6 \mathrm{~V}$ with a scan rate of $0.1 \mathrm{~V} / \mathrm{s}$ and frequency of $100 \mathrm{kHz}$. To separate the effects of the radical treatments on insulator and ferroelectric layer, the $\mathrm{SiO}_{2}$ used in this experiment was not treated beforehand. The memory window was slightly were increased about $0.3 \mathrm{~V}$ by the nitrogen and oxygen radical treatment. But capacitance of the MFIS in accumulation region was increased with oxygen radical treatment and reduced with nitrogen radical treatment due to the radical treatment processes. It is clear that the good memory window hysteresis are observed, which indicates that the charge injection, the charge trapping, and the ion drift effect are suppressed in the $\mathrm{Pt} / \mathrm{SBT} / \mathrm{SiO}_{2} / \mathrm{n}-\mathrm{Si}$ structure with the treated SBT.

The current density through $\mathrm{Pt} / \mathrm{SBT} / \mathrm{SiO}_{2} / \mathrm{n}-\mathrm{Si}$ structure, J, using as-deposited and the nitrogen-treated or oxygen-treated SBT thin films were measured as a function of applied voltage V. As shown in Fig. 17, the nitrogen and oxygen treatment succeeded in decreasing the current density. The decreases of currents are considered to be attributed to property of surface of SBT thin films. In after SBT suffering the irradiation treatment, the roughness of 
surface morphology reduces. The difference barrier height of the SBT surface with $\mathrm{SiO}_{2}$ and $\mathrm{Pt}$ also increase so absolutely the leakage current through $\mathrm{Pt} / \mathrm{SBT} / \mathrm{SiO}_{2}$ will be reduced. It is found that the nitrogen radical treatments are more efficient than oxygen radical treatments in term of reduce leakage current. The current density through SBT films were analyzed into two main contributions, from the Schottky and the Frenkel-Poole conduction Fig. 18.

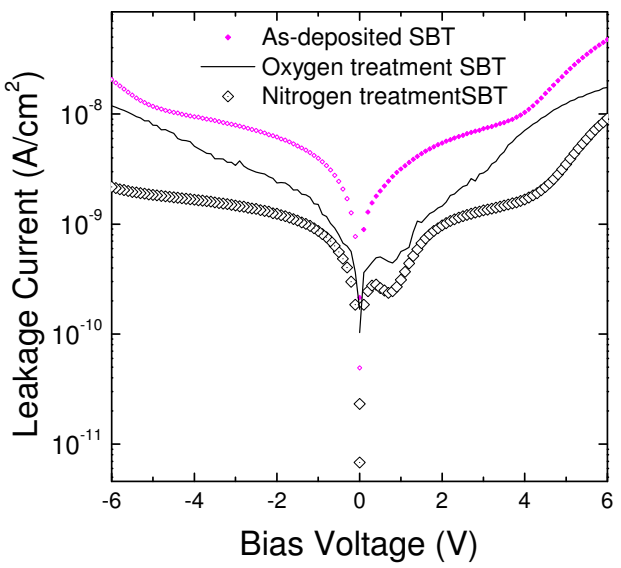

Fig. 17. I-V characteristics of $\mathrm{Pt} / \mathrm{SBT} / \mathrm{SiO} 2 / \mathrm{n}-\mathrm{Si}$ with and without radical irradiation treatments
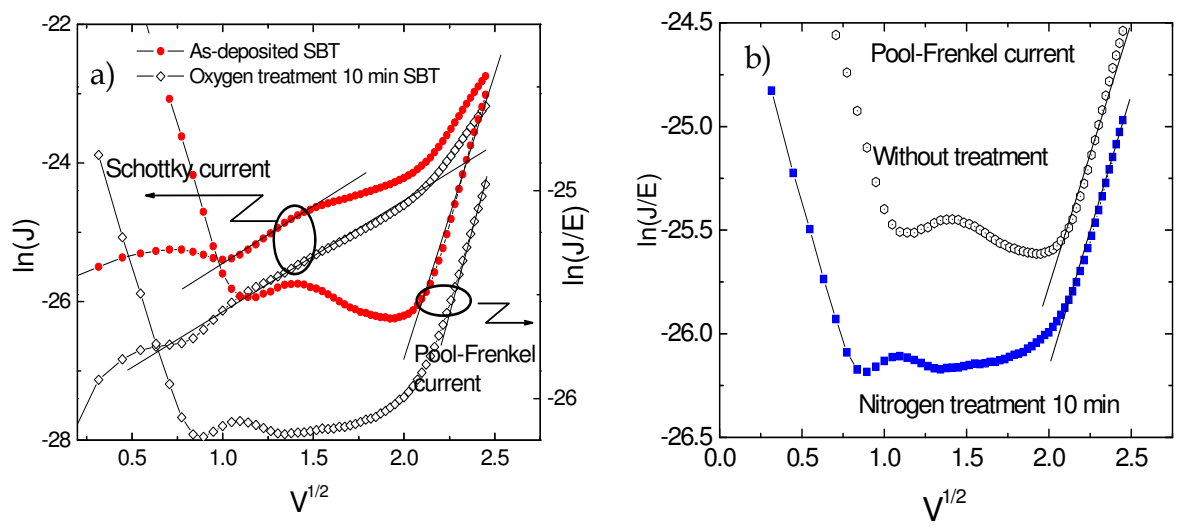

Fig. 18. The leakage current characteristics of MFIS structure, representing Schottky emission at low field and Poole-Frenkel emission at high field, with SBT a) as-deposition and oxygen $10 \mathrm{~min}$ and b) nitrogen treatment $10 \mathrm{~min}$. E is electric field.

It is found that the Schottky conduction played a key role in total conduction in the nitrogen and oxygen treatment SBT, and consists of carrier transport brought about by thermionic emission across the metal-ferroelectric interface at a low electric field, whereas the Frenkel- 
Poole conduction is dominant in the as-deposited SBT, and brought about by field-enhanced thermal excitation of trapped carriers into the band [Takahashi, M. etc., (2001)]. Therefore, reduction of the current density shown in Fig. 17 is attributed to the fact that after the nitrogen and oxygen treatment the SBT have increased the barrier height of the ferroelectric in both accumulate and depletion states. Fig. 18 shows phenomenon of the Frenkel-Poole conduction reduced, became an insignificant minority in modified SBT and so the trap density in the ferroelectric layer may be decreased in the irradiation processes.

\section{Improvements of $\mathrm{Pt} / \mathrm{SBT} / \mathrm{SiO}_{2} / \mathrm{n}$-Si MFIS characteristics with $\mathrm{SiO}_{2}$ and $\mathrm{SBT}$ layers treated by nitrogen radical}

To understand more about effects of nitrogen treatments on improve characteristics of $\mathrm{Pt} / \mathrm{SBT} / \mathrm{SiO}_{2} / \mathrm{n}-\mathrm{Si}$ MFIS structures, two samples of $\mathrm{A}$ and $\mathrm{B}$ were investigated by $\mathrm{C}-\mathrm{V}$ and I$\mathrm{V}$ curves and retention time properties. The first sample was fabricated without using any improvement for reference. The other sample were treated by the nitrogen radical irradiation to the $\mathrm{SiO}_{2}$ insulator and SBT ferroelectric thin film in fabrication processes to improve MFIS's characteristics. The second sample was treated by nitrogen radical with 60 min for $\mathrm{SiO}_{2}$ and 20 min for SBT.

\subsection{Nitrogen radical treatment to improves MFIS's electrical properties}

Fig. 19 a) shows the C-V characteristics of MFIS structures with and without nitrogen treatment, and show counter-clockwise hysteresis loops controlled by polarization of ferroelectric SBT. They were measured at $100 \mathrm{kHz}$ by sweeping the gate voltage from inversion to accumulation region and then sweeping back. The sweeping voltage changes between $\pm 6 \mathrm{~V}$ with a scan rate of $0.1 \mathrm{~V} / \mathrm{s}$. The memory window is about $1.3 \mathrm{~V}$ of sample A without nitrogen treatment and $1.8 \mathrm{~V}$ of sample $\mathrm{B}$ with nitrogen treatment for $\mathrm{SiO}_{2}$ and SBT. It is found that a larger memory window and flatter depletion capacitance of sample B in comparison with that of sample A. It is believed that suppression of charge injection, charge trapping, and ion drift effect phenomenon are cause of the improvements.

The leakage current density through $\mathrm{Pt} / \mathrm{SBT} / \mathrm{SiO}_{2} / \mathrm{n}-\mathrm{Si}$ structures was investigated to verify contribution of the nitrogen treatment to both buffer and ferroelectric layers. As shown in Fig. $19 \mathrm{~b}$ ), the samples of $\mathrm{SiO}_{2}$ with the nitrogen treatment for $60 \mathrm{~min}$ and SBT with treatment for $20 \mathrm{~min}$ succeeded in decreasing the leakage current density in comparison with sample without the treatment. But the measurements exhibits a distinct difference between samples with and without 20 min nitrogen treatment for SBT, and the leakage current reduced one order of magnitude. The currents are considered to be attributed to property of SBT thin films as they are very sensitive to the nitrogen treatment.

In our previous report [Hai, L. V., etc. (2008)], the current density through deposited-SBT films were analyzed into two main contributions, those are the Schottky and the FrenkelPoole conduction. It is also found that only the Schottky conduction played a key role in total conduction in the nitrogen treatment SBT, and consists of carrier transport brought about by thermionic emission across the metal-ferroelectric interface at a low electric field, whereas the Frenkel-Poole conduction is dominant in the as-deposited SBT, and brought about by field-enhanced thermal excitation of trapped carriers into the band. Therefore, the decreased contributions from the current density shown in Fig. 19 b) suggest that the SBT 
with the nitrogen treatment have increased the barrier height of the ferroelectric in both accumulation and depletion states.
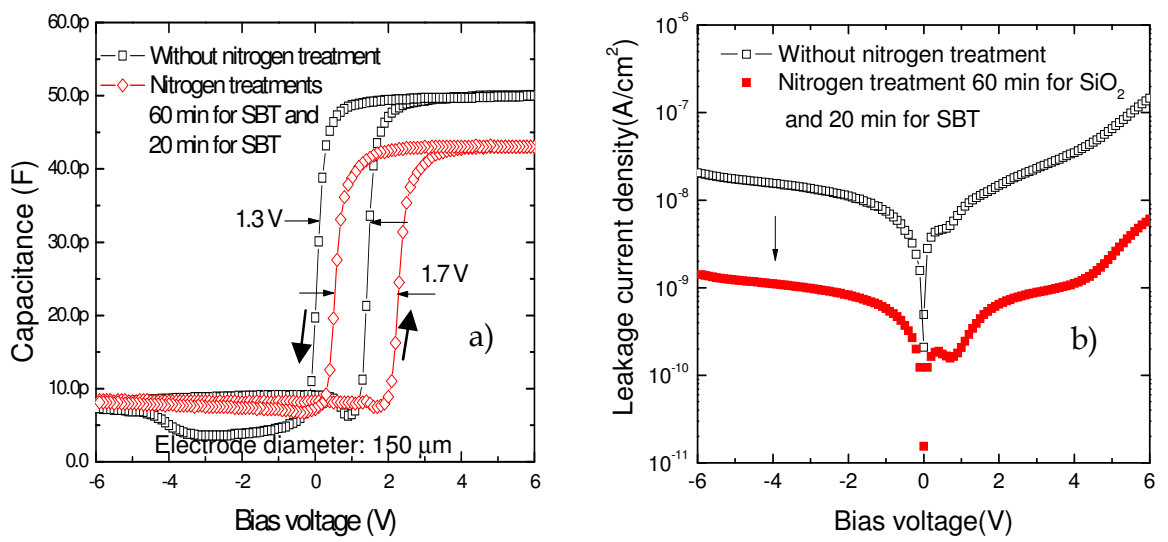

Fig. 19. Pt/SBT/ $/ \mathrm{SiO}_{2} / \mathrm{n}-\mathrm{Si}$ MFIS structures with and without nitrogen treatment for $\mathrm{SiO}_{2}$ and SBT thin films, a) C-V characteristics and b) I-V characteristics.

All the results in above part of this study indicated that the chemistry incorporation of nitrogen in the interlayer of both $\mathrm{SiO}_{2}$ and SBT play a key role in determining electron characteristics of MIS and MFIS structure.

\subsection{Memory retention characteristics of capacitance of the MFIS structures}

For checking non-volatility of the MFISs, retention characteristics were measured. Fig. 20 shows memory retention characteristics of capacitance of the Pt/SBT $/ \mathrm{SiO}_{2} / \mathrm{n}-\mathrm{Si}$ diodes, which were measured at room temperature. The write pulses of $\pm 6.0 \mathrm{~V}$ amplitude and $0.1 \mathrm{~s}$ width were initially applied to the gate, and changes in capacitance versus time were measured. Fig. 20 a) shows retention characteristic of MFIS without treatment, that shows the ON/OFF states can be kept in constant no longer than 3 hours after the write operation in MFIS without treatment. Fig. $20 \mathrm{~b}$ ) shows retention characteristic of MFIS with using nitrogen treatment $\mathrm{SiO}_{2}$ and oxygen treatment SBT that shows the ON/OFF states were measured for 7 days after the write operation. Fig. 20 c) shows retention characteristic of MFIS with using nitrogen treatment $\mathrm{SiO}_{2}$ and SBT that shows the ON/OFF states were measured for 23 days after the write operation.

We believe that the retention is strongly correlated to the magnitude of leakage current density through the stacked gate insulator and ferroelectric layers. The first sample A without the treatment processes exhibited the leakage current larger about 10 times than that of sample B. As we know, nitrogen treatment not only improved surface of SBT but also improved interface layer of SBT and buffer layer. The Ferroelectric SBT films gather many advantage in characteristics over other ferroelectric compounds, for application in ferroelectric memory which include a fatigue-free behavior, good retention properties and low leakage currents [Paz de Araujo, C.A., etc., (1995)]. But they require a high temperature annealing $\left(700^{\circ} \mathrm{C} \sim 800^{\circ} \mathrm{C}\right)$ for crystallization that is main cause of constituent- element diffusion from the ferroelectric film into and the insulator layer in Pt/SBT/ $\mathrm{SiO}_{2} / \mathrm{n}$-Si MFIS structure [Kim, W. S., (2002), Li, Y., 
(2007)]. Damage of the $\mathrm{SiO}_{2}$ buffer layer seriously degrades device performance [Kim, W. S., etc., (2002), Li, Y., etc., (2007), Aguilar, G. G., etc., (2006)]. Therefore, Pt/SBT/ $\mathrm{SiO}_{2} / \mathrm{n}-\mathrm{Si}$ MFIS structure could not give good characteristics without any treatment processes and be used for any ferroelectric memory devices.
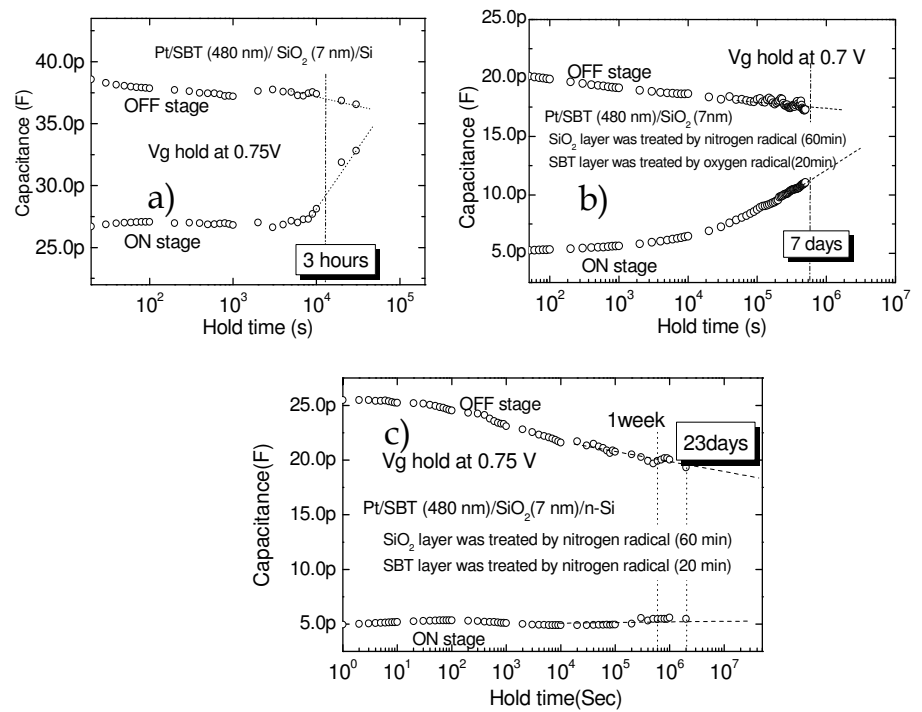

Fig. 20. Retention characteristics of the $\mathrm{Pt} / \mathrm{SBT} / \mathrm{SiO}_{2} / \mathrm{n}-\mathrm{Si}$ MFIS structures, a) without using radical irradiation, b) with 60-min nitrogen treatment for $\mathrm{SiO}_{2}$ and 20-min oxygen treatment for SBT and c) with treatment for $\mathrm{SiO}_{2}$ and SBT layers by nitrogen radical irradiation for 60 min and 20min, respectively.

With the nitrogen radical treatments the $\mathrm{SiO}_{2}$ layer was become a stronger barrier to limit the diffusion problem of the Pt/SBT/ $\mathrm{SiO}_{2} / \mathrm{n}-\mathrm{Si}$ structure [Hai, L.V., etc., (2009)]. Damage of $\mathrm{SiO}_{2}$ by diffusion problems was also suppressed. Both the oxygen radical treatment and nitrogen radical treatment can improve the interface layer of $\mathrm{SBT}$ and $\mathrm{SiO}_{2}$ gate by reducing the interface trap density [Hai, L.V., etc., (2006 a)]. The improvement of C-V hysteresis loop with larger memory window, steep switching were proofs of interface trap density decrease after treatment $\mathrm{s}$.

Although, the oxygen radical irradiation treatment could be effective method to enhance the retention time of $\mathrm{Pt} / \mathrm{SBT} / \mathrm{SiO}_{2} / \mathrm{n}$-Si MFIS structure, but the nitrogen irradiation treatment is absolutely better. The $\mathrm{C}-\mathrm{V}$ retention measurement shown in fig. $20 \mathrm{c}$ ) revealed that the capacitance ratio of ON/OFF stage does not undergo any significant change after 23 days of measurement. A good retention property of MFIS capacitor indicated 10 year retention times by their extrapolated lines.

\section{Conclusions}

In summary, we have successfully investigated the characterization of the $\mathrm{Pt} / \mathrm{SBT} / \mathrm{SiO}_{2} / \mathrm{n}$ Si MFIS structures and demonstrated a novel method to improve their retention properties. 
The nitrogen and oxygen radical irradiation treatments applied for the $\mathrm{SiO}_{2}$ and SBT were analyzed and evaluated about their efficiency and effect on the Pt/SBT/SiO $2 / n-S i$ MFISs' characteristics.

Investigations of treated-SiO${ }_{2}$ and $\mathrm{SBT}$ surfaces reveal that nitrogen radicals are incorporated on thin films and modified chemical composition of surface layer. With nitrogen radical treatment $\mathrm{SiON}_{\mathrm{x}}$ was formed and is beneficial to the suppression of elemental interdiffusion of the $\mathrm{SBT} / \mathrm{SiO}_{2}$ interface. Chemical bonding of SBT surface layer were by the nitrogen and oxygen radical irradiation treatment modified and become stronger. It is cause of improvement electrical properties of SBT layer.

When nitrogen radical treatment was applied for the $\mathrm{SiO}_{2}$ and SBT films, the retention and electrical characteristics of $\mathrm{Pt} / \mathrm{SBT} / \mathrm{SiO}_{2} / \mathrm{n}-\mathrm{Si}$ was enhanced remarkably. The memory window of C-V hysteresis increased about from $1.3 \mathrm{~V}$ to $1.8 \mathrm{~V}$ when $V_{g}$ is swept between \pm $6 \mathrm{~V}$. The leakage current is reduced more than one order of magnitude. The retention characteristic show good behavior for a long retention time, and was measured for 23 day with no significant change.

It is concluded that nitrogen and oxygen radical irradiation treatments contribute to enhance performance of the Pt/SBT/ $\mathrm{SiO}_{2} / \mathrm{n}$-Si. Furthermore, These methods can be applied for improving SBT thin films using in various structures of ferroelectric memory devices.

\section{References}

Paz de Araujo, C.A., Cuchiaro J.D., Mcmillan, L.D., Scott, M.C., Scott, J.F. (1995), Nature 374 (1995) 627.

Riviere, J. C. (1983). Practical Surface Analysis by Auger and X-ray Photoelectron Spectrocopy, John Wiley\&Sins, Ltd., chap 2, p.48-53.

Klee, M. and Macken, U. (1996). Integrated Ferroelectric, 12, 11

Park, Y.-B., Lee, J.-K., Jung, H.-J., Park, J.-W.,(1999), Bismuth composition control of $\mathrm{SrBi}_{2} \mathrm{TaNbO}_{9}$ thin films by heat treating $\mathrm{Bi}_{2} \mathrm{O}_{3}$-inserted heterostructure J. Mater. Res. 14 (1999) 2986.

Tanaka, M., Watanabe, K., Katori, K, Yamoto, H., Yagi, H. (1998). J. Korean Phys. Soc. 32 : S1504.

Hai, L. V., Kanashima, T., Okuyama, M. (2006 a). Improvement of electrical properties and memory retention in MFIS structure by nitrogen radical irradiation of $\mathrm{SiO}_{2}$ buffer layer, Proceedings of The 6th elopan-Korea Conference on Ferroelectricity, Tohoku University, Sendai, Japan.

Hai, L. V., Kanashima, T., Okuyama, M. (2006 b). Improvement of memory retention in metal-ferroelectric-insulator-semiconductor structure by $\mathrm{SrBi}_{2} \mathrm{Ta}_{2} \mathrm{O}_{9}$ surface modification induced by nitrogen and oxygen radical irradiation, Integrated Ferroelectrics, Volume 84, Issue 1, pages 179-186.

Takahashi, M., Kodama, K., Nakaiso, T., Noda,M. and Okuyama, M.,(2001). Effect of leakage current through ferroelectric and insulator on retention characteristics of metalferroelectric-insulator-semiconductor structure, Integrated Ferroelectrics, 40 (2001) 125.

Takahashi, M., Noda, M. and Okuyama, M. (2003). Photoyield and x-ray-photoelectron spectroscopic studies of $\mathrm{O}_{2}$-annealing effects on $\mathrm{SrBi}_{2} \mathrm{Ta}_{2} \mathrm{O}_{9}$ thin films prepared by pulsed laser deposition, J. Appl. Phys. 94, 1912 (2003) .

Hai, L. V., Kanashima, T., Okuyama, M. (2008). Enhancement Of Memory Retention Time Of MFIS With SBT Ferroelectric And SiO2 Buffer Layers Treated By Nitrogen Radical Irradiation, Integrated Ferroelectrics , Vol. 96, Issue 1, 2008, Pages 27-39. 
Sakai, S. \& Takahashi, M. (2010). Recent Progress of Ferroelectric-Gate Field-Effect Transistors and Applications to Nonvolatile Logic and FeNAND Flash Memory, Materials 2010, 3, 4950-4964.

Ishiwara, H. (2001). Current Status and Prospects of FET-type Ferroelectric Memories, Journal of semiconductor technology and science, vol.1, no. 1, march 2001.

Dawber, M., Rabe, K. M., Scott, J. F.,(2005). Physics of thin-film ferroelectric oxides, reviews of modern physics, volume 77, October 2005.

Hai, L. V., Takahashi, M \& Sakai, S. (2010). Fabrication and characterization of sub-0.6- $\mu \mathrm{m}$ ferroelectric-gate field-effect transistors, Semicond. Sci. Technol. 25 (2010) 115013 (5pp).

Tarui Y, Hirai T, Teramoto K, Koike H and Nagashima K (1997).Appl. Surf. Sci. 113656.

Scott, J. F. (2000). Ferroelectric Memories (Berlin: Springer), chapter 12.

Sakai, S. \& Ilangovan, R. (2004). IEEE Electron Device Lett., 25 369- 71.

Wang. S., Takahashi, M., Li, Q-H, Takeuchi, K. and Sakai, S. (2009). Semicond. Sci. Technol. 24105029

Hatanaka, T., Yajima, R., Horiuchi, T., Wang, S., Zhang, X., Takahashi, M., Sakai, S. \& Takeuchi, K. (2009). Symp. on VLSI Circuits (16-18 June 2009, Kyoto, Japan) Dig. of Tech. Papers pp 78- 79.

Aizawa, K., Park, B. E., Kawashima, Y., Takahashi, K., \& Ishiwara, H., (2004). Impact of $\mathrm{HfO}_{2}$ buffer layers on data retention characteristics of ferroelectric-gate field-effect transistors, Appl. Phys. Lett. 85 (2004) 3199.

Seo, Y. J., Kim, K. C., Kim, H. D., Joo, M. S., An, H. M., Kim, T. G. (2008) Correlation between charge trap distribution and memory characteristics in metal/oxide/nitride /oxide/silicon devices with two different blocking oxides, $\mathrm{Al}_{2} \mathrm{O} 3$ and $\mathrm{SiO}_{2}$, Applied Physics Letters, Aug. 2008,Vol. 93 6,p. 063508 - 063508-3.

Kim, W. S., Yi W., Yu S. G., Heo J., Jeong T., Lee J., Lee, C. S., Kim, J. M.,Jeong, H. J., Shin Y. M., \& Lee, Y. H., (2002), Secondary electron emission from magnesium oxide on multiwalled carbon nanotubes, Appl. Phys. Lett. 81, 1098 (2002).

Li, Y., Zhang, S., Fei, W, Sritharan, T., Xu, S., (2007), Nd-substituted $\mathrm{SrBi}_{2} \mathrm{Ta}_{2} \mathrm{O}_{9}$ ferroelectric thin films prepared by radio frequency magnetron sputtering, Thin Solid Films 515 (2007) 8371- 8375.

Aguilar, G. G., Wu, A., Reis, M. A., Ramos, A. R., Salvado, I. M. M., Alves, E., Costa, M. E. V., (2006), Diffusion processes in seeded and unseeded SBT thin films with varied stoichiometry, Surface Science 600 (2006) 1780-1786

Hai, L. V., Kanashima, T., Okuyama, M. (2009)., Enhancement of Memory Retention Time of Metal/Ferroelectric/Insulator/Semiconductor Structure by Using Fast Annealing and Nitrogen Radical Irradiation, J. of the K. Phys. Soci., Vol. 55, No. 2, August 2009, pp. 884_887.

Youa, I.-K., Leea, W.J., Yanga, II-S.,Yua, B.G., Choa, K.I., Kimb S.H., (2001), Effect of $\mathrm{NO}\left(\mathrm{Si}_{3} \mathrm{~N}_{4} / \mathrm{SiO}_{2}\right)$ layers on the electrical properties of MFIS using SBT $\left(\mathrm{SrBi}_{2} \mathrm{Ta}_{2} \mathrm{O}_{9}\right)$ materials, Integrated Ferroelectrics: An International Journal, Volume 33, Issue 1 \& 4, 2001, Pages 177 - 184. 


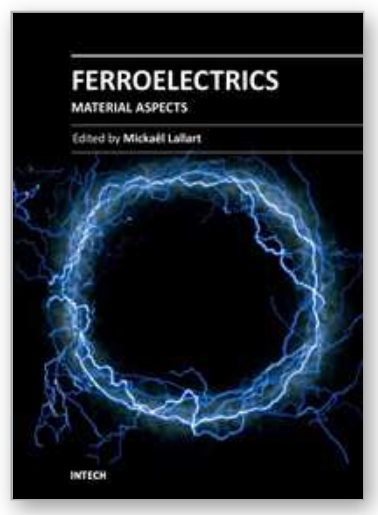

\author{
Ferroelectrics - Material Aspects \\ Edited by Dr. MickaÃ«l Lallart
}

ISBN 978-953-307-332-3

Hard cover, 518 pages

Publisher InTech

Published online 24, August, 2011

Published in print edition August, 2011

Ferroelectric materials have been and still are widely used in many applications, that have moved from sonar towards breakthrough technologies such as memories or optical devices. This book is a part of a four volume collection (covering material aspects, physical effects, characterization and modeling, and applications) and focuses on ways to obtain high-quality materials exhibiting large ferroelectric activity. The book covers the aspect of material synthesis and growth, doping and composites, lead-free devices, and thin film synthesis. The aim of this book is to provide an up-to-date review of recent scientific findings and recent advances in the field of ferroelectric materials, allowing a deep understanding of the material aspects of ferroelectricity.

\title{
How to reference
}

In order to correctly reference this scholarly work, feel free to copy and paste the following:

Le Van Hai, Takeshi Kanashima and Masanori Okuyama (2011). Studies on Electrical and Retention Enhancement Properties of Metal-Ferroelectric-Insulator-Semiconductor with Radical Irradiation Treatments, Ferroelectrics - Material Aspects, Dr. MickaÃ«I Lallart (Ed.), ISBN: 978-953-307-332-3, InTech, Available from: http://www.intechopen.com/books/ferroelectrics-material-aspects/studies-on-electrical-and-retentionenhancement-properties-of-metal-ferroelectric-insulator-semicond

\section{INTECH}

open science | open minds

\section{InTech Europe}

University Campus STeP Ri

Slavka Krautzeka 83/A

51000 Rijeka, Croatia

Phone: +385 (51) 770447

Fax: +385 (51) 686166

www.intechopen.com

\section{InTech China}

Unit 405, Office Block, Hotel Equatorial Shanghai

No.65, Yan An Road (West), Shanghai, 200040, China 中国上海市延安西路65号上海国际贵都大饭店办公楼405单元

Phone: +86-21-62489820

Fax: +86-21-62489821 
(C) 2011 The Author(s). Licensee IntechOpen. This chapter is distributed under the terms of the Creative Commons Attribution-NonCommercialShareAlike-3.0 License, which permits use, distribution and reproduction for non-commercial purposes, provided the original is properly cited and derivative works building on this content are distributed under the same license. 